\title{
ELE TEM DOIS PAPAIS: AS NOVAS FAMÍLIAS NA LITERATURA INFANTIL CONTEMPORÂNEA
}

\author{
HE HAS TWO DADS: NEW FAMILIES IN CONTEMPORARY CHILDREN'S \\ LITERATURE
}

DOI: http://dx.doi.org/10.23926/RPD.2526-2149.2019.v4.n2.p514-523.id454

\author{
Epaminondas de \\ Matos Magalhães \\ Doutor em Literatura (PUC- \\ RS) \\ Docente IFMT Campus \\ Pontes e Lacerda - Fronteira \\ Oeste \\ Docente PPGEN-IFMT, \\ PPGEL-UNEMAT \\ epaminondas.magalhaes@pl \\ c.ifmt.edu.br
}

\section{Marcos Aparecido \\ Pereira}

Mestre em Ensino (IFMT)

Doutorando em Estudos

Literários (UNEMAT)

Docente IFMT Campus

Cáceres - Prof. Olegário

Baldo

marcos.pereira@cas.ifmt.edu .br
Resumo: O presente texto busca discutir em que medida a literatura infantil contemporânea problematiza questões polêmicas, entre elas, a homossexualidade, tema atual no contexto social e na literatura, haja vista que é integrante direta das relações do homem e da sociedade e, desta maneira, tais questões não podem ser desconsideradas. Para tanto, tomaremos como ponto de partida a obra Meus dois pais, de Walcyr Carrasco, para tecer algumas considerações acerca dessa literatura infantil contemporânea e de sua importância no fomento à formação humana dentro e fora do espaço escolar, desmistificando conceito pré-estabelecidos e verdades padronizadas.

Palavras-chave: Homossexualidade; Família; Literatura infantil.

\begin{abstract}
The present text seeks to discuss how contemporary children's literature problematizes controversial issues, including homosexuality, current theme in the social context and also in the literature, since it is a direct component of the relations of the men and society; so, such topic cannot be disregarded. Therefore, we will take as a starting point the text My two fathers, by Walcyr Carrasco, to make some considerations about this contemporary children's literature and its importance in fomenting human formation inside and outside the school space, demystifying pre-established concepts and truths standardized.
\end{abstract}

Keywords: Homosexuality; Family; Children's literature. 


\section{INTRODUÇÃO}

A temática das diferenças vem ganhando destaque nos estudos culturais, sociológicos e literários nas duas últimas décadas por meio de uma busca analítica dos novos fenômenos sociais e como eles constroem uma nova identidade para o sujeito. Somos sabedores que esse cenário só vem sendo alterado devido aos diversos movimentos sociais ao longo do tempo, estudos científicos e, consequentemente, as novas legislações em vigor que contribuem para a alteração do cenário sociocultural e político em relação às diferenças.

Contudo, há que se considerar que a homossexualidade ainda está envolta em uma série de mitos e preconceitos. Desta forma, compreende-se que discutir, desmistificar e, sobretudo, libertar essa temática das amarras de uma visão deturpada é papel das diversas instâncias sociais, entre elas a escola.

O espaço escolar é o espaço do conhecimento, do esclarecimento, da diversidade e do respeito, logo é campo fundamental para o rompimento de ideias preconceituosas que ferem as relações sociais humanas. O indivíduo precisa conhecer, perceber a complexidade e a diversidade das interações humanas a fim de que essas relações deixem de ser vistas como antinaturais, estranhas. Nesta perspectiva de quebra de preconceitos, a leitura, em especial a literária, devido ao seu caráter de representatividade e de identificação do sujeito leitor, tem papel imprescindível, visto que é ela que pode levar o sujeito à compreensão da multiplicidade humana na sociedade.

Por sua vez, a literatura infantil, que, durante séculos esteve ligada às questões pedagógicas e da formação do sujeito, vem ganhando um novo viés e dedicando-se às temáticas contemporâneas que estão na base dos estudos de caráter social e cultural. Entretanto, é preciso lembrar que temáticas como a da homossexualidade e/ou da constituição de famílias por casais homoafetivos são muito raras nas produções infantis. Diante disso, nos perguntamos: quais motivos levam a esse silenciamento? $\mathrm{O}$ que impede que esse assunto seja amplamente explorado nesse tipo de produção?

Sabe-se que o maior entrave para os estudos e discussões acerca dessas questões está diretamente ligado ao preconceito, pois, segundo Facco (2009, p. 69), “[...] o sujeito homossexual ainda é condenado à invisibilidade, inclusive discursiva”. Apesar da aparente modernidade, no sentido de evolução em pleno século XXI, ainda é comum excluir das narrativas (exceto às sarcásticas), não querer ver casais homossexuais livremente pelas ruas, não querer conviver com gays ou lésbicas; e mais: usar termos como "tolerar" e "aceitar" o outro, como se a opção sexual do outro fosse um fardo irremediável. Silva (2000) explica que 
o exercício da tolerância pedagogicamente aplicado às pessoas desde a idade escolar geralmente deixa de levar em conta e, sobretudo, questionar as relações de poder que produzem figuras dicotômicas dentro deste cenário: por um lado a figura do dominante tolerante ou a identidade hegemônica benevolente e de outro a figura do dominado tolerado ou a identidade subalterna respeitada.

Palavras como homossexual, bissexual, transgêneros, uranistas, sodomitas, dentre outros surgem como variação do que Michel Foucault (1980) apontou como sujeitos da "espécie homo", ao referir-se às novas e possíveis relações afetivas que estão (e sempre estiveram no interior da sociedade), mas que, como destacado, são, comumente forçadas à invisibilidade.

Com relação à literatura, a polêmica em torno dessas relações ganhou força com algumas obras publicadas a partir de 2010. Obras essas que se iniciaram com títulos sugestivos para crianças: O gato que gostava de cenoura (1999), de Rubem Alves; Menino ama menino (2000), de Marilene Godinho; O menino que brincava de ser (1986), de Georgina da Costa Martins; O amor não escolhe sexo (1996), de Giselda Laporta Nicolelis.

Diante desse cenário é importante questionar: os mediadores de leitura estão aptos a trabalhar com as questões de homossexualidade com as crianças? O Programa Nacional Biblioteca Escolar (PNBE) e Programa Nacional do Livro Didático (PNLD) traz obras e discussões acerca da temática? Livros literários com essa temática são lidos nas escolas pelos docentes?

Nos últimos quinze anos tivemos uma série de obras que tematizam as questões étnico raciais, a exemplo: Pretinha, eu?, de Júlio Emílio Braz; a obra mato-grossense, Cabelo ruim: uma história de três meninas tentando se aceitar, de Neuza Baptista Pinto. Além disso, surgem também obras que tratam de pessoas vivendo com HIV, como: Dias difíceis, Fanny Abramovich; AIDS, e agora? Entre outros. Contudo, constatamos que a temática da homossexualidade ainda vem sendo tratada e discutida de forma tímida, muitas vezes encontrando inúmeras barreiras, como, por exemplo, as sabidas polêmicas em torno da rejeição de livros didáticos que continham imagens de casais homoafetivos. Por isso, nosso objetivo, é, sobretudo, discutir essa temática, ainda pouco abordada auxiliando a ampliar os horizontes de reflexão acerca do assunto.

Ramos (2009, p. 296) afirma que a "sexualidade, e em particular a que é dissonante do paradigma heteronormativo, continua a ser um universo tido quase como intocável, alvo de recriações tão esporádicas quanto distanciadas, pelo menos no que à edição portuguesa diz respeito". No Brasil, o cenário não é diferente, mas, mesmo assim, há produções como: $O$ 
menino que brincava de ser, de Georgina Martins; Sempre por perto, de Anna Cláudia Ramos; Eu é um outro, de Hermes Bernardi Jr.; Do jeito que a gente é, de Márcia Leite; e Sofia e Mônica, de Leonardo Brasiliense e a obra que analisaremos: Meus dois pais, de Walcyr Carrasco.

Ramos ainda menciona que a:

\begin{abstract}
transposição literária de um tema com fundas implicações sociológicas, para além dos atávicos constrangimentos morais e religiosos, explicará o relativo silêncio que sobre ele se tem abatido, sintomático de um desconforto mais geral, sobretudo quando se trata de um diálogo axiológico desigual entre adultos e crianças. (RAMOS, 2009, p. 296).
\end{abstract}

Nesse sentido, percebe-se que ainda existem inúmeros entraves que dificultam a inserção dessa temática em discussões permeadas pela leitura literária de forma que essas discussões possam auxiliar a combater o silenciamento da homossexualidade dentro do espaço escolar. Neste sentido, torna-se vital pensar as "novas famílias" representadas na literatura infantil contemporânea, em especial as ligadas à homossexualidade.

Entraves como o do pensamento tradicionalista, das convicções ideológicas e religiosas dificultam o amplo trabalho de questões que acabam se tornando polêmicas devido a multiplicidade de sujeitos sociais envolvidos e suas diferentes concepções; essas que, muitas vezes, não abrem espaço para a diversidade de pensamento em comportamentos e segregam o diferente à invisibilidade e ao silenciamento.

\title{
2 ELE TEM DOIS PAPAIS: AS NOVAS FAMÍLIAS NA LITERATURA INFANTIL CONTEMPORÂNEA
}

As obras infantis Meus Dois Pais (Walcyr Carrasco), Olívia tem Dois Papais (Márcia Leite), Eu tenho Duas Mães (Márcia Martelli) são construídas em sentido convergente ao tratar da temática da homossexualidade a partir da constituição de "novas famílias", em que uma das figuras parentais é duplicada: dois pais ou duas mães.

Nessas obras, mas em especial na obra que nos propusemos a analisar, estamos diante de uma sociedade em que se percebe um novo formato de família, a homoparental, que podemos constatar a partir dos pontos de vista do narrador, de seus personagens, e das imagens gestadas no interior da obra. Podemos destacar também que as imagens possuem uma gama de significados, principalmente quando lidamos com texto infanto-juvenil, assim, é fundamental perceber como a criança receberá esse texto, como ela encara esse novo cenário e essas novas constituições afetivas.

O Projeto de Lei 612/2011 que alterou o Código Civil e reconheceu a união estável de pessoas do mesmo sexo e trouxe a possibilidade de conversão dessa união em casamento, sem 
dúvida provocou mudanças no cenário social. Neste contexto, discutir o tema da homoafetividade nesse contexto contemporâneo é algo positivo, necessário e quase obrigatório se tomarmos por base que a escola prepara o aluno para a plena atuação na vida em sociedade, logo, não se pode fugir ou omitir temáticas presentes na convivência social moderna.

Se há formação de casais homossexuais, se há a possibilidade de união entre pessoas do mesmo sexo com a finalidade construção de família e se esse tipo de constituição, infelizmente, ainda provoca algum tipo de polêmica, é fundamental que haja discussão dessa temática já na educação fundamental a fim de proporcionar tanto o esclarecimento necessário às crianças que certamente terão contato cedo ou tarde com esse novo tipo de constituição familiar, bem como a eliminação do preconceito nas gerações futuras.

A escola é uma das instituições responsáveis por promover as discussões acerca da temática apresentada e um dos mecanismos, se assim podemos dizer, que pode atuar nesse processo, levando em consideração o caráter humanizador da literatura, destacado por Antonio Candido (2011). Logo, é a literatura, em especial, a literatura infantil durante o ensino fundamental, um imprescindível veículo de contato, percepção, reflexão e construção do mundo e, por sua vez, de constituição do ser humano e de suas relações culturais e sociais.

Sendo a escola esse espaço tão fundamental na formação, é preciso lembrar dos atores capazes de impulsionar essas e outras discussões dentro da escola: os professores. O que nos remete à urgência das discussões acerca desse tipo de temática também dentro dos cursos de licenciatura, a fim de problematizar, esclarecer e ampliar os conhecimentos dos futuros educadores para que tal questão não sofra violência simbólica e física dentro dos espaços sociais.

Nesse sentido, é relevante aos educadores, principalmente os que atuam no ensino fundamental questionar-se de que maneira a literatura infantil aborda o tema da homoafetividade e das novas famílias. Obviamente porque essas constituições familiares estão cada vez mais presentes no cotidiano dentro e fora das escolas, em segundo lugar porque ainda durante o ensino fundamental aparecem os primeiros interesses sexuais -afetivos, logo, é importante que a escola possa dar suporte ao jovem de forma ele encontre respaldo emocional, social e racional, haja vista que o processo de descoberta da sexualidade não é um processo simples e previamente construído e/ou definido.

Em se tratando da literatura infantil, Silva (2011, s.p.) demonstra que:

os novos sentidos que o gênero literário infantil brasileiro vem dando às questões de ordem do gênero e da sexualidade, apontando especificamente para a construção de 
sujeitos homoafetivos convivendo na diversidade, e para as novas parcerias ou uniões civis que refletem também, numa proporção indireta do tema, a formação de novos lares e famílias sob a ordem homoparental.

Walcyr Carrasco é reconhecido muito mais pelas dramaturgias, em especial, as telenovelas. Contudo, o autor tem uma narrativa infantil que trata especificamente da temática da homossexualidade, no que tange, o lugar da criança dentro desse cenário, Meus dois pais. Na obra em questão, a narrativa é desenvolvida de forma mais madura, a voz narrativa é a da criança (narrador em primeira pessoa), que trata da união do pai com outro homem e como o ele [filho] lida com essa descoberta.

A narrativa se inicia com as discussões do pai e da mãe e, posteriormente, a separação. Inicialmente, é importante destacarmos o olhar da criança diante da separação, como algo sempre negativo a ela, pois o maior medo da criança é o abandono. Tal temática é muito bem representada em outro texto infantil, Tchau, de Lygia Bojunga, em que a criança tem que saber lidar, sem o elemento mágico, com a separação dos pais.

Nesse ponto, o protagonista de Meus dois pais encara com mais naturalidade a questão da separação, do que outros textos observados na década de 80 e início de noventa. O que deixa clara a transformação social da época. Na escola, por exemplo, Naldo, o protagonista, não se sente tão diferente, pois é mais um que possui uma família em que os pais são separados. Isso demonstra, sob um olhar mais sociológico, que os espaços (neste caso o escolar) estão mais acessíveis ao cenário da separação, que rompe com os pressupostos da família tradicional. O que nos leva, de maneira inevitável, a novas constituições familiares observadas por esse mesmo protagonista: filhos de pais diferentes (em virtude de uniões familiares diversas); filhos de "produção independente"; filhos que não moram com os pais, etc.

Como qualquer criança, o protagonista busca entender o que está acontecendo no "mundo dos adultos" e daquela separação. Ele vai descobrindo aos poucos, pelas pistas ao longo de conversas e frases proferidas pela mãe e pela avó. Percebe que há um grande mistério, ainda proibido a ele, pois ao questionar a mãe e a avó, elas sempre se esquivam das respostas.

Na despedida, meu pai me abraçou bem forte:

- Naldo, tem muita gente contra mim.

- Por que, papai? Ele ficou emocionado.

E disse aquela frase horrível que os mais velhos usam quando não querem falar de alguma coisa.

- Mais tarde você vai entender.

Que raiva! Por que eles têm essa mania de achar que, por ser mais novo, eu não vou entender? 
Eu ia responder que já sou bem crescido, quando ele me abraçou de novo:

- Mas eu não vou desistir de você! Fiquei sem voz.

Desistir de mim? Então o caso era muito sério! Sozinho, eu pensava:

- O que o papai fez de tão errado? Por que não querem que eu fique com ele?

(CARRASCO, 2010, p. 15, grifo nosso)

A voz do menino diante de "o que o papai fez de tão errado? Por que não querem que eu fique com ele?" reflete, claramente, a visão de sociedade acerca da homossexualidade, tratando-a como um erro e, até certa medida, esses sujeitos precisam ser segregados da sociedade e da família, ao se assumirem gays ou lésbicas.

É interessante destacarmos que até a década de 1960 os homossexuais eram tratados sobre várias formas de preconceito: doentes, imorais e indignos. O que não quer dizer que após essa década as formas de preconceito mudaram, mas, significa que as formas de resistência e discussões vêm sendo alteradas, implementadas pelos movimentos LGBT. Sabemos que ainda hoje tratar das questões homoafetivas, homoeróticas é algo repleto de tabu dentro do contexto escolar e social, mesmo diante de tantas mudanças, ainda vivemos um cenário de preconceito.

No trecho "Naldo, tem muita gente contra mim", percebemos a visão de uma sociedade demarcada pelo preconceito. A maior parte do preconceito se deve ao não entendimento dos sujeitos sobre a homossexualidade, em especial, por parte do adulto, que acaba se refletindo na criança. É possível notar que há o julgamento, ou talvez fosse melhor dizer a condenação das pessoas pela escolha do pai.

O mundo infantil é, via de regra, muito simples, sem preconceitos, completamente aberto ao que os adultos consideram novo, diferente ou até mesmo impossível. As formas de rejeição e de preconceito são construídas ao longo dos tempos e por sua vez transmitidas às gerações, influindo nas percepções das crianças e levando-os a repetir o comportamento dos adultos.

Ainda no excerto anterior, talvez pela demarcação da visão da sociedade sobre a temática, vemos que o adulto subestima a criança no que se refere a capacidade desta de compreender a nova vida e o novo relacionamento do pai. Entretanto, é preciso frisar que este tipo de "não compreensão" está ligado aos adultos e não às crianças que são capazes de ver o mundo sob uma óptica descomplicada dos entraves sociais. Entraves sociais que levam os personagens do texto (e as pessoas representadas por eles) ao drama, ao sofrimento e a ameaça de abdicação, neste caso, do amor pelo filho, quando num abraço emocionado o pai promete não desistir do filho. 
$\mathrm{Na}$ narrativa, aos poucos, o protagonista vai sendo excluído pelos colegas, em virtude do posicionamento das famílias acerca da homossexualidade do pai.

Convidei o Paulo e o Fê pra fazer um trabalho de grupo.

(...) Nem acreditei quando eles recusaram o meu convite.

- A minha mãe me proibiu de ir no seu apartamento - disse o Fê.

Fiquei chateado. Quis saber o motivo.

- É por causa do seu pai.

O Fê se afastou sem querer falar muito.

Fui atrás.

- O que o meu pai tem de errado?

Os dois ficaram sem jeito, até que o Fê disparou:

- Seu pai é gay, Naldo! (CARRASCO, 2010, p. 21, grifo nosso)

O preconceito acerca do pai de Naldo se deve não às crianças em si "os dois ficaram sem jeito", mas às construções identitárias dos pais, que proíbem as crianças de irem à casa do protagonista. Ou seja, o preconceito não é inato ao homem, mas é uma construção histórica e discursiva. Diante do preconceito de gênero, o sujeito sofre uma violência simbólica, como afirma Bourdieu (2003). Essa violência está ligada, diretamente, a "lógica da dominação", dominação masculina, em que divide o mundo entre "normal" e "anormal".

violência simbólica, violência suave, insensível, invisível a suas próprias vítimas, que se exerce essencialmente pelas vias puramente simbólicas da comunicação e do conhecimento, ou, mais precisamente, do desconhecimento, do reconhecimento ou, em última instância, do sentimento (BOURDIEU, 2003, p. 7-8).

Diante da revelação, Naldo se afasta do pai e passa a morar com a avó. Somente após a intervenção da mãe é que ele aceita, de certa forma, o pai. No diálogo com a mãe a criança pergunta se por viver com o pai e seu companheiro, ele ficaria como eles. Percebe-se com isso, que o olhar da criança revela todos os paradigmas estereotipados de uma sociedade preconceituosa e que não aceita as diferenças de gênero. A avó paterna, ao falar da questão do senso comum de que em sendo criado por gays, assim serão, responde: "a maioria dos gays veio de lares tradicionais" (CARRASCO, 2010, p. 21).

$\mathrm{Na}$ fala da avó, teríamos um questionamento aos leitores: Como os leitores encaram essa quebra de paradigmas? Sabemos que ainda hoje existe o pensamento da família tradicional, o preconceito às relações homoafetivas e a exclusão do diferente, logo, esse tipo de narrativa suscita debates dentro e fora do espaço escolar levando o leitor e por sua vez aqueles quem têm contato com ele à diferentes realidades e pontos de vista, ao questionamento das verdades 
únicas e absolutas e, também, à reconstrução do senso comum imposto por construções sóciohistóricas.

Se tomarmos por base o Método Recepcional (AGUIAR; BORDINI, 1988), teríamos neste ponto a ruptura do horizonte de expectativas do leitor, ou seja, o abalo das certezas e dos costumes socialmente moldados de nossa sociedade levando-o ao questionamento das verdades impostas e do senso comum. O questionamento do horizonte de expectativas, por sua vez, amplia a visão do leitor, neste caso o aluno, sobre o mundo, as relações pessoais e a diversidade sóciocultural que nos circunda e que, inevitavelmente precisa ser levada em conta em nossas leituras dentro das ficções e, principalmente, fora dela.

Teresa Colomer (2008) aponta que esse tipo de temática faz parte das novas características da literatura infantil contemporânea, pois traz os novos cenários culturais e sociais em que as crianças se encontram inseridas. Logo, o que se percebe com a obra analisada é a tentativa de se problematizar a questão da homossexualidade parental como forma estável de vivência capaz de abarcar as mesmas características da família tradicional. Dessa forma, é um grito em defesa, até certa medida, da tentativa de legitimar essas novas constituições familiares, colocando-as para coexistirem na mesma esfera da família tradicional.

\section{CONSIDERAÇÕES FINAIS}

A literatura representa a sociedade e por meio desse processo mimético leva de volta para a sociedade a possibilidade de enfretamento de temáticas caras aos sujeitos, uma vez que os personagens que vivem nas narrativas levam-nos a pensar e viver outras realidades problematizando experiências e discutindo a inter-relação dos indivíduos no mundo.

Desta forma, ao tratar de temáticas como a homossexualidade em obras de literatura infantil, os autores como Walcyr Carrasco proporcionam de uma forma receptiva às crianças o contato com problemas como o preconceito, a intolerância, etc. O que, por sua vez, leva a reflexão sobre as diferentes constituições de família no mundo contemporâneo e como a sociedade lida com essas novas e diferentes constituições.

Entretanto, é preciso lembrar que os mediadores do texto também precisam ser qualificados ainda nos cursos de licenciatura a fim de estarem aptos a combater a violência simbólica no espaço escolar quando assuntos como as relações homoafetivas forem discutidas.

Por fim, a narrativa analisada é rica em questões que podem ser discutidas em sala de aula a fim de trabalhar os novos modelos de família existentes, fomentando debates sobre modelos únicos de encarar o mundo, desmistificando pontos de vista unilaterais e 
preconceituosos e, principalmente, combatendo discriminações e silenciamentos sóciohistóricos referentes às relações afetivas das pessoas.

\section{REFERÊNCIAS}

AGUIAR, Vera Teixeira de; BORDINI, Maria da Glória. Literatura: a formação do leitor: alternativas metodológicas. Porto Alegre: Mercado Aberto, 1988.

BOURDIEU, P. A dominação masculina. 3 ed. Rio de Janeiro: Bertrand Brasil, 2003.

CANDIDO, Antonio. Vários escritos. Rio de Janeiro: Ouro sobre Azul, 2011.

CARRASCO, Walcyr. Meus dois pais. Ilustrações de Laurent Cardon. São Paulo: Ática, 2010 .

FACCO, Lúcia. Era uma vez um casal diferente: a temática homossexual na educação literária infanto-juvenil. São Paulo: SUMMUS, 2009.

RAMOS, Ana Margarida. Saindo do armário - Literatura para a infância e a reescrita da homossexualidade. Forma Breve, n. 7, 2009. Disponível em:

http://revistas.ua.pt/index.php/formabreve/article/view/2298 Acesso em: 28 abr. 2019.

SILVA, Antonio de Pádua Dias da. Uma nova configuração na literatura infantil brasileira: o discurso de e sobre a homoafetividade e a família homoparental. IN: XII congresso Internacional da ABRALIC. Curitiba UFPR. 2011.

SILVA, Tomaz Tadeu da. A produção social da identidade e da diferença. In: SILVA, Tomaz Tadeu da (Org.) Identidade e diferença. Rio de Janeiro: Vozes, 2000.

Recebido em: 12 de maio de 2019. Aprovado em: 24 de novembro de 2019. 